\title{
Synthesis of New Liquid-Crystalline Selenophenes via Electrophilic Cyclization of (Z)-Selenoenynes
}

\section{Daniel S. Rampon (PG), Aloir A. Merlo (PQ) and Paulo H. Schneider (PQ)}

Instituto de Química, Departamento de Química Orgânica, UFRGS, Avenida Bento Gonçalves, 9500,

Campus do Vale, Porto Alegre, RS, Brasil, 91501-970

*paulos@iq.ufrgs.br

Keywords: Liquid Crystals, Selenophenes, Electrophilic Cyclization.

\section{INTRODUCTION}

Organic chalcogenides are widely studied in development of organic materials with technological interest. ${ }^{1}$ In addition, these compounds also have a diverse array of important biological effects. ${ }^{2}$ In this context, heterocycles containing chalcogen atoms, specially thiophene, play an important role in development of $\pi$-rich molecules for architecture of organic semiconductors, conducting polymers and electroluminescent materials. ${ }^{3}$ Despite the potential of chalcogenophenes as constituent units of conducting polyconjugated systems, only few examples of liquid-crystalline compounds containing selenophene and tellurophene are investigated. ${ }^{4}$ Thus, taking in consideration our program towards the synthesis of molecules containing a chalcogen atom, ${ }^{5}$ we decided by the first time develop new liquid-crystalline selenophenes 1, employing electrophilic cyclization of (Z)-selenoenynes 2 (Scheme 1). ${ }^{6}$ To the best of knowledge, this is the first report of selenophenes to construction of achiral liquid crystals materials.

\section{RESULTS AND DISCUSSION}

The synthesis of 2,5-selenophenes derivates begins with preparation of terminal acetylenes, ${ }^{5}$ which were converted into the respective 1,3-diynes (3) by oxidative homocoupling. ${ }^{7}$

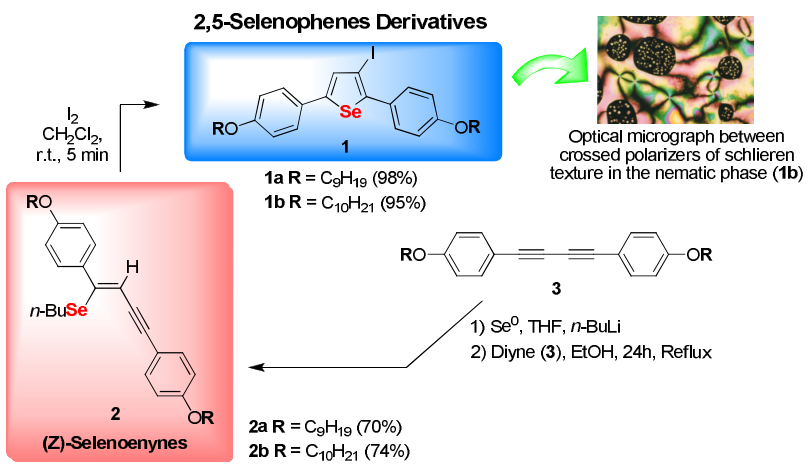

Scheme 1. Synthesis of new liquid-crystalline selenophenes via electrophilic cyclization.

Treatment of intermediates 3 with hydroselenation conditions afforded the compounds $2 \mathbf{a}-\mathbf{b}$. Finally, electrophilic cyclization of (Z)-selenoenynes provided the 2,5-selenophenes $1 \mathbf{a}-\mathbf{b}$ in excellent yields. The thermal behavior of the selenophenes was investigated by means of polarizing optical microscopy (POM) and differential scanning calorimetry (DSC) (Table 1).

Table 1. Phase transition temperatures $\left({ }^{\circ} \mathrm{C}\right)$ for selenophenes-LC 1a-b.

\begin{tabular}{c|l|c}
\hline LC & Cycle & Phase sequence \\
\hline \multirow{2}{*}{ 1a } & Heating & $\mathrm{Cr} \mathrm{30.6} \mathrm{I}$ \\
& Cooling & $\mathrm{I} 1.8 \mathrm{Cr}$ \\
\hline 1b & Heating & $\mathrm{Cr} 42.7 \mathrm{~N} 53.0 \mathrm{I}$ \\
& Cooling & $\mid \mathrm{I} 50.8 \mathrm{~N}-24.0 \mathrm{Cr}$ \\
\hline
\end{tabular}

${ }^{a}$ On heating; $\mathrm{Cr}=$ crystal phase; $\mathrm{N}=$ nematic phase; $\mathrm{I}=$ isotropic phase.

Compound $\mathbf{1 b}$ exhibited an enantiotropic nematic phase, which surprisingly was extended until low temperatures in the cooling cycle, demonstrating the potential of these materials for technological applications. Continued investigations of these novel selenophenes-LC are underway in our laboratory, aiming the synthesis of symmetrical and non symmetrical selenophenes and expanding the scope for tellurophene analogs.

\section{CONCLUSION}

In summary, we have shown a straightforward synthesis of new liquid-crystalline 2,5-selenophenes derivatives that displays an attractive mesomorphic behavior. More studies exploring the molecular structure are ongoing, also aiming expanding the structure for tellurophene analogs.

\section{ACKNOWLEDGEMENTS}

CAPES, CNPq, INCT-Catalysis, FAPERGS and UFRGS.

\section{REFERENCES}

${ }^{1}$ (a) Patra, A.; et al. Chem. Mater. 2011, 23, 896. (b) Coropceanu, V.; et al. Chem. Rev. 2007, 107, 926.

${ }^{2}$ Zeni, G.; et al. Chem. Rev. 2004, 104, 6255

${ }^{3}$ Perepichka, I.; et al. Handbook of Thiophene-based Materials. 2009, Wiley-VCH.

${ }^{4}$ Seed, A.; et al. Mol. Cryst. Liq. Cryst. 1997, 299, 19.

5 (a) Rampon, D. S.; et al. J. Mat. Chem. 2010, 20, 715. (b) Rampon, D.; et al. J. Braz. Chem. Soc. 2010, 21, 2100.

${ }^{6}$ Zeni,G.; et al. J. Org. Chem. 2007, 72, 6726.

${ }^{7}$ Yin, K.; Li, C.; Li, G.; Jia, X. Green Chem. 2011, 13, 591. 